Linköpings Studies in Science and Technology. Dissertations No. 88

\title{
FILTERING AND RECONSTRUCTION IN IMAGE PROCESSING
}

\author{
By \\ Hans Knutsson
}

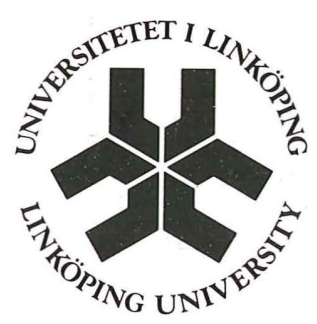

Linköping University

Department of Electrical Engineering

Linköping, Sweden

1982 
Front cover image produced on the GOP Image Processor ISBN 91-7372-595-1

Printed in Sweden by VTT-Grafiska, Vimmerby 1982 
Till U1la Kaisa 

"Like ourselves, I replied; and they see only their own shadows, or the shadows of one another, which the fire throws on the opposite wall of the cave"

P1ato (The Repub1ic) 



\section{ACKNOWLEDGEMENTS}

I am greatly indebted to my supervisor Professor Goesta Granlund for the constant inspiration and research guidance that he provided throughout the course of this work. Through our countless hours of stimulating discussions he has helped me to see the problems of image processing in a wider context. Professor Paul Edholm originated the ideas for the principle of Ectomography and his deep insights into the medical and technical fields were of major importance for the development of the method. Professor Ingemar Ingemarsson has provided many valuable comments and useful suggestions. The collaboration with Dr Roland Wilson has resulted in a flow of novel ideas and been of inestimable value for the work on image coding and image enhancement. He has also willingly devoted many hours to correct and improve the formulations in this dissertation. Dr Christer Petterson work on simulations was essential for the completion of the studies in Ectomography. I am deeply indebted to Bertil von Post for the numerous hours of programming and software guidance he spent to make much of this research work possible. The daily discussions with my colleagues Martin Hedlund and Kenneth Lundgren have been of great value for my work and the GOP Image Processing group as a whole has provided a very stimulating environment. Yvonne Färnström has been most helpful when typing my manuscripts. Marianne Anse-Lundberg helped me with figures and sketches. Many of my friends an colleagues in the Department of Electrical Engineering and also in the Department of Mathematics have helped me in various occasions. The financial support for the work in this dissertation was partly provided by grants from the Swedish National Board for Technical Development. 


\section{CONTENTS}

Acknowledgements $\ldots \ldots \ldots \ldots \ldots \ldots \ldots \ldots \ldots \ldots \ldots \ldots \ldots \ldots$

List of papers included in the dissertation $\ldots \ldots \ldots \ldots . . .3$

Introduction $\ldots \ldots \ldots \ldots \ldots \ldots \ldots \ldots \ldots \ldots \ldots \ldots$

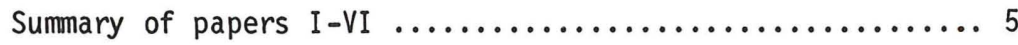

Ectomography. A New Radiographic Method for Reproducing a Selected Slice of Varying Thickness ............ I-1

References ................................ I-9

Ectomography A New Radiographic Reconstruction

Method - I. Theory and Error Estimates ............... II -1

References...$\ldots \ldots \ldots \ldots \ldots \ldots \ldots \ldots \ldots \ldots \ldots$ II -8

Ectomography. A New Radiographic Reconstruction

Method - II. Computer Simulated Experiments ............ II I-1

References ........................................ II -7

Design of Convolution Kernels $\ldots \ldots \ldots \ldots \ldots \ldots \ldots \ldots$ IV -1

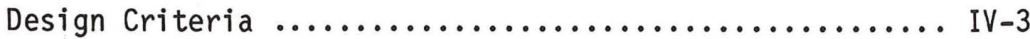

Optimization of Kernels ...................... IV -15

Processing Experiments ....................... IV -28

Appendix A-E ............................. IV -50

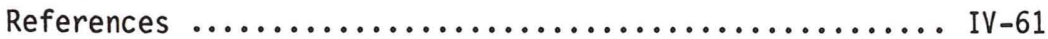

Anisotropic Non-Stationary Estimation and its App-

lications. Part I: Restoration of Noisy Images .......... V-1

Figures ................................ V-18

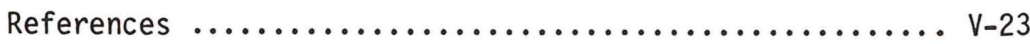

Anisotropic Non-Stationary Estimation and its App-

lications. Part II: Predictive Image Coding ............. VI -1

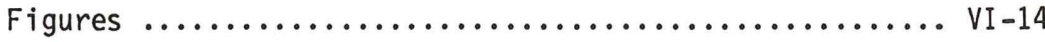

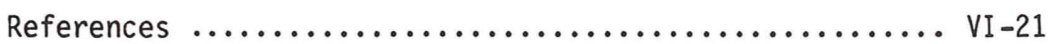


I Edholm, P., Granlund, G., Knutsson, H.E. and Petersson, C.U. (1980). Ectomography. A New Radiographic Method for Reproducing a Selected S1ice of Varying Thickness. Acta Radiol. Diagnosis, 21, 433-442.

II Knutsson, H.E., Edholm, P., Granlund, G.H. and Petersson, C.U. (1980). Ectomography - A New Radiographic Reconstruction Method - I. Theory and Error Estimates. IEEE Trans. Biomed. Eng., BME-27, 640-648.

II I Petersson, C.U., Edholm, P., Granlund, G.H. and Knutsson, H.E. (1980). Ectomography - A New Radiographic Reconstruction Method - II. Computer Simulated Experiments. IEEE Trans. Biomed. Eng., BME-27, 649-655.

IV Knutsson, H.E. (1982). Design of Convolution Kernels. Internal report LiTH-ISY-I-0557. To be published.

V Knutsson, H.E., Wilson, R., Granlund, G.H. (1982). Anisotropic Non-Stationary Image Estimation and its Applications. Part I: Restoration of Noisy Images. Accepted for publication in IEEE Trans. Communications.

VI Wilson, R., Knutsson, H.E., Granlund, G.H. (1982). Anisotropic Non-Stationary Image Estimation and its Applications. Part II: Predictive Image Coding. Accepted for publication in IEEE Trans. Communications. 


\section{INTRODUCTION}

Image processing covers a wide range of problems, from edge/1ine detection to pattern recognition and reconstruction. Its areas of application include medical diagnosis, cartography, character recognition, robot vision and telecommunications. The methods used in these areas are similarly diverse.

A common thread which binds all these problems together is the fundamental need for the execution of one or more filtering operations. The design of filter algorithms that perform a specified task is therefore central to a majority of image processing applications. This dissertation illustrates this commonality.

The first three papers deal with the problems of reconstruction from projections. They describe the development of a new tomographic method designated Ectomography. This method is novel in that it allows reconstruction of an arbitrarily thick layer of an object using limited viewing angle.

The last three papers concern the estimation of local image properties, such as orientation and frequency, and the use of these methods in application algorithms. The concept of two-dimensional quadrature filters is introduced and serves as a basis for obtaining phase independent local estimates. Such estimates of orientation and local variance allow for an extension of the classical Wiener filter, which is shown to be effective in image enhancement and image coding. 
I Ectomography - A New Radiographic Method for Reproducing a Selected Slice of Varying Thickness

A new radiographic principle for demonstrating a slice of the human body is described. Because the slice is depicted as if it had been excised (ectomized) from the object, the new principle is designated ectomography. The novelty of the method is that it enables the reconstruction of a well-defined slice of a body using a limited view angle. Unlike ordinary C.T. it is therefore possible to directly reconstruct slices in any orientation relative to the body. In addition the width of the slice can easily be varied by means of changing filter parameters.

The principle is based on the same projection system as in tomosynthesis. In ectomography, $\mathrm{N}$ component images are exposed. The $x$-ray tube moves in a circular path in a horizontal plane above the reclining patient. Underneath the $x$-ray table is the image detector, also moving in a horizontal pathway. The directions of the central $x$-ray beam thus form two cones with their tips in the patient. The component images so produced are then digitized and fed into a computer, where they are appropriately filtered and summed to a new image, an ectomogram. 
II Ectomography - A new Radiographic Reconstruction Method - I. Theory and Error Estimates

Radiographic technology has advanced considerably during recent years with the advent of reconstruction techniques allowing visualization of slices through the body. In spite of the advantage of computed tomography compared to conventional radiographic methods, there are still some shortcomings with the method. If a different section of the body is desired, another recording has to be made, the width of the slice reconstructed is fixed, and a ful1 $180^{\circ}$ view angle is required.

In this paper a new method, ectomography, is proposed for the next-generation radiographic reconstruction systems, where these shortcomings are overcome. The principle of ectomography is basically one of producing reconstructions of desired object slices by summing appropriately filtered two-dimensional projections of this object. The filtering is carried out in the Fourier domain and a class of filter functions are derived that will enable users to obtain a reconstruction that is optimal with respect to slice thickness, signal-to-noise ratio, and resolution.

The method does indeed require some investment in data storage and processing power, but given the fast development in these fields the approach is by no means unrealistic. 
II Ectomography - A New Radiographic Reconstruction Method II. Computer Simulated Experiments

Ectomography is tested by means of computer simulations. The equipment used was an Alpha LSI-2 computer with 64 kbyte of core memory and 10 mbyte of disc memory.

The four filter functions derived in paper II, together with a filter function corresponding to conventional tomography (tomosynthesis) were tested.

Simulated ectomograms using 64 "exposures" were computed for a series of different objects, located at various distances from the sharply depicted tomographic plane. They were then presented as three-dimensional reliefs.

For each situation a series of component images, each with a different filter function, was calculated. Six different objects were used, with three sizes of each, making eighteen objects in al1.

The simulated ectomograms are presented in relief form, together with the correct cross sectional image for comparison. From this comparison it may be concluded that all four filter methods are superior to the unfiltered ones. Furthermore, the filter function seems to sharpen the edges, so that after filtering, the image will have higher contrast than the band-limited original image. 
IV Design of Convolution Kernels

Operators for extraction of local information are essential components in an image processing system. This paper concentrates on the design and evaluation of convolution kernel sets enabling easy estimation of local orientation and frequency.

Consideration of interpolation properties and the limiting effects of the uncertainty principle leads to the definition of an "ideal" quadrature filter function. An optimization procedure is utilized to produce pairs of convolution kernels which realize an approximation of the desired function. A number of optimization results are presented.

To evaluate the performance of the optimized kernels in an image processing task, a series of experiments have been carried out. Examples are given of local orientation and frequency estimates for images with different signal to noise ratios. An angle deviation measure is defined and a vector averaging scheme is introduced to increase angle estimation accuracy. Using a $0 \mathrm{~dB}$ SNR testimage, orientation estimates are produced having an expected deviation of less than 7 degrees. 
V Anisotropic Non-Stationary Image Estimation and its Applications. Part I - Restoration of Noisy Images

A new form of image estimator, which takes account of linear features, is derived using a signal equivalent formulation. The estimator is shown to be a non-stationary linear combination of three stationary estimators. The relation of the estimator to human visual physiology is discussed. A method for estimating the nonstationary control information is described and shown to be effective when the estimation is made from noisy data. A sub-optimal approach which is computationally less demanding is presented and used in the restoration of a variety of images corrupted by additive white noise. The results show that the method can improve the quality of noisy images even when the signal-noise ratio is very low. 
VI Anisotropic Non-Stationary Image Estimation and its Applications. Part II - Predictive Image Coding

\begin{abstract}
A new predictive coder, based on an estimation method which adapts to line and edge features in images, is described. Quantization of the prediction error is performed by a two-level adaptive scheme: an adaptive transform coder; threshold coding in both transform and spatial domains. Control information, which determines the behaviour of the predictor, is quantized using a simple variable rate technique. The results are improved by pre-and post-filtering using a related non-causal form of the estimator. Acceptable images have been produced in this way at bit rates of less than 0.5 bit/pixel.
\end{abstract}




\section{REFERENCES}

1 Granlund G.H. In Search of a General Picture Processing Operator. Computer Graphics and Image Processing, Vol. 8, pp 155178.

2 Hube1, D.H., Wiesel, T.N. Brain Mechanisms of Vision. Scientific American, Sept., 1979

3 Gabor, D. Theory of Communication. Proc. IEE., 93, 26, pp 429461,1946

4 Papoulis, A. Systems and Transforms with Applications in Optics. New York, McGraw-Hi11 Book Company, pp 197-199, 1968

5 Daugman, J.G. Two-dimensional Analysis of Cortical Receptive Field Profiles. Vision Res. 20, pp 846-856, 1980

6 Granlund G.H. GOP: A Fast and Flexible Processor for Image Analysis. Languages and Architectures for Image Processing, M.J.B. Duff and S. Levialdi, eds, Academic Press, 1981

7 Granlund G.H. and Arvidsson J. The GOP Image Computer. Computer Vision, O.D. Faugeras, ed, Cambridge University Press, 1983

8 Marr, D., Hildreth, E. Theory of Edge Detection, AI memo No 518, MIT, 1979

9 Fiasconaro, J.G. Two-dimensional Non-Recensive Filters in Picture Processing and Digital Filtering. T.S. Huang, ed, Berlin, Springer-Verlag, ch 3, 1976

10 Bracewe11, R. The Fourier Transform and its Applications. McGraw-Hi11 Book Company, 1965 
